\title{
Microsurgical Treatment of Optic Nerve Metastasis: Case Report and Review of the Literature
}

\author{
Sl. Kondoff ${ }^{*}{ }^{*}$, M. Milev ${ }^{1}$, Chr. Tzekov ${ }^{1}$, T. Spiriev ${ }^{1}$, L. Laleva ${ }^{1}$, G. Kirova ${ }^{2}$, Chr. Kostadionova ${ }^{3}$ \\ ${ }^{1}$ Department of Neurosurgery, Tokuda Hospital Sofia, Sofia, Bulgaria \\ ${ }^{2}$ Department of Medical Imaging Diagnostics, Tokuda Hospital Sofia, Sofia, Bulgaria \\ ${ }^{3}$ Department of Anesthesiology, Tokuda Hospital Sofia, Sofia, Bulgaria \\ Email: "slavi.kondoff.@gmail.com
}

Received 13 October 2015; accepted 13 November 2015; published 16 November 2015

Copyright (C) 2015 by authors and Scientific Research Publishing Inc.

This work is licensed under the Creative Commons Attribution International License (CC BY).

http://creativecommons.org/licenses/by/4.0/

c) (i) Open Access

\begin{abstract}
Metastatic lesions to the eye and optic nerve have incidence of $12 \%$ and are observed predominantly in patients, diagnosed with breast and lung cancer. However, isolated involvement of the optic nerve by breast cancer metastasis is much rarely reported with only 13 cases reported in the literature by $\mathbf{2 0 1 3}$, according to Cherkaev et al., that were often preoperatively misdiagnosed. Herewith we present a rare case of optic nerve metastasis in a previously diagnosed breast cancer patient. Review of the literature was done with analysis of the diagnostic difficulties that these cases present and the role of the neurosurgeon in the management of the patients.
\end{abstract}

\section{Keywords}

Optic Nerve Metastasis, Surgical Treatment, Breast Cancer

\section{Introduction}

Metastases to the eye and optic nerve are by no means a rare finding with reported incidence rates of up to $12 \%$ [1]. Dissemination from primary breast cancer accounts for one quarter to nearly half of the cases. However, isolated involvement of the optic nerve is much rarely reported. Only 13 cases have been described in the literature by 2013 and preoperative misdiagnosis is a usual phenomenon with these lesions [1]. Therefore, this type of lesion requires further and more thorough exploration as they present complex diagnostic problems. Herewith

\footnotetext{
"Corresponding author.
}

How to cite this paper: Kondoff, Sl., Milev, M., Tzekov, Chr., Spiriev, T., Laleva, L., Kirova, G. and Kostadionova, Chr. (2015) Microsurgical Treatment of Optic Nerve Metastasis: Case Report and Review of the Literature. Case Reports in Clinical Medicine, 4, 352-355. http://dx.doi.org/10.4236/crcm.2015.411071 
we present a rare case of optic nerve metastasis in a previously diagnosed breast cancer patient. Review of the literature was done.

\section{Case Report}

A female 59-year-old patient presented with long-term progressive loss of visual acuity. The patient was referred to a neurosurgeon after loss of vision in the right eye, clinical examination demonstrating sings of congestive retinopathy and MRI findings of lesion in the area of the right opto-carotid triangle region.

The patient had been diagnosed with ductal carcinoma of the right breast 20 years ago (1993). She had undergone mastectomy and postoperative radiotherapy with satisfactory (local) disease control. 15 years later the patient had presented with pain in the right thoracic region and dyspnea. The clinical evaluation and CT of the thoracic cavity had revealed tumor formation in the right lung and pericardial effusion. Pericardiotomy, pleurodesis and tumor biopsy had been performed and the histological examination of the biopsy material had revealed metastasis from breast carcinoma.

Less than a month later the patient had begun experiencing loss of visual acuity for the right eye. The ophthalmological examination had found progressive loss of vision due to serous retinal detachment in the right eye with unaffected left eye. Bevacizumab had been selected as treatment in the form single intravitreal application.

After referral to the neurosurgeon, the differential diagnosis of meningioma and metastasis in the region wes discussed. Additionally, computed tomography angiography was performed (Figure 1). A decision was made for operative intervention and the lesion was successfully managed by microsurgical excision (Figure 2). No recurrence was found on the follow up MRI examination (Figure 3). Unfortunately, the vision of the affected eye remained unchanged. Intraoperative diagnosis was optic nerve metastasis, which was later confirmed by histological examination of the biopsy material.
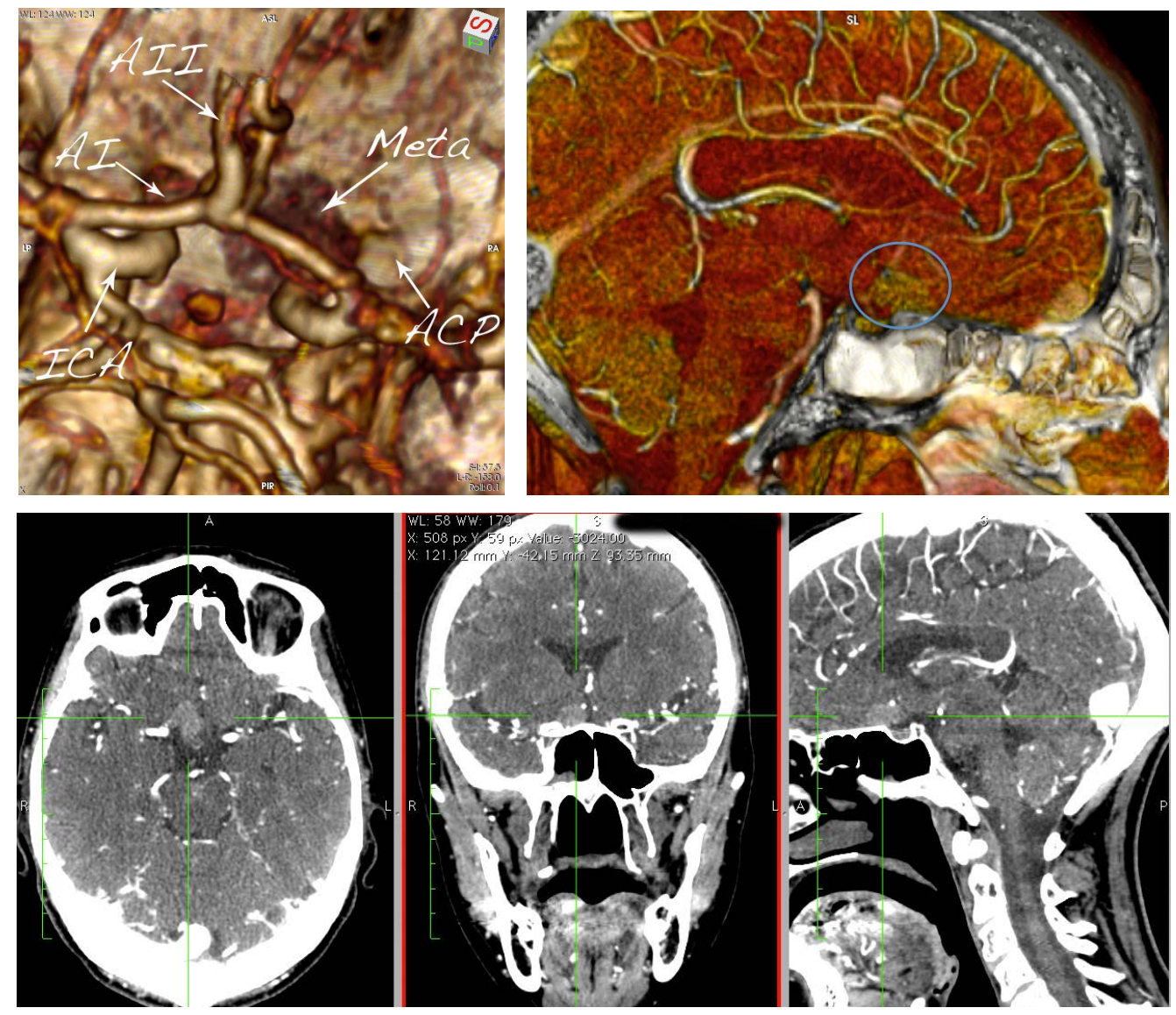

Figure 1. Preoperative CT and Osirix based 3D reconstructions (Version 5.8.1; Free download from http://www.osirix-viewer.com/) presenting the localization of the metastasis. 


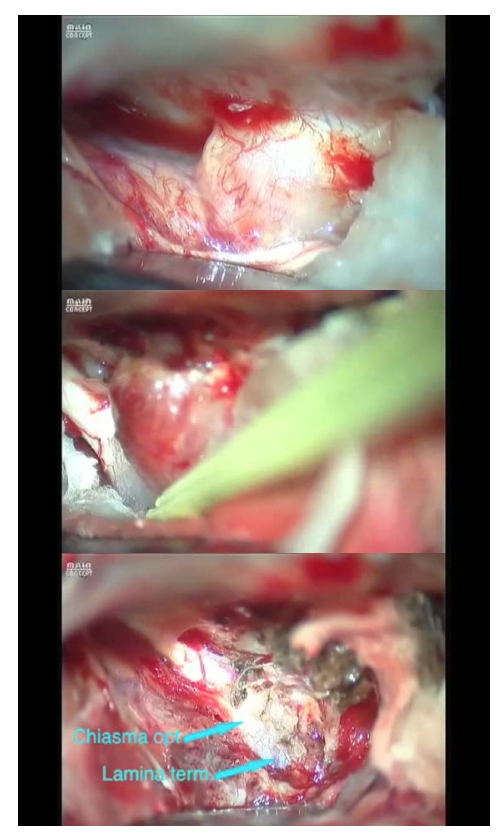

Figure 2. Intraoperative images showing main steps in the resection of the tumor trough right pterional approach.

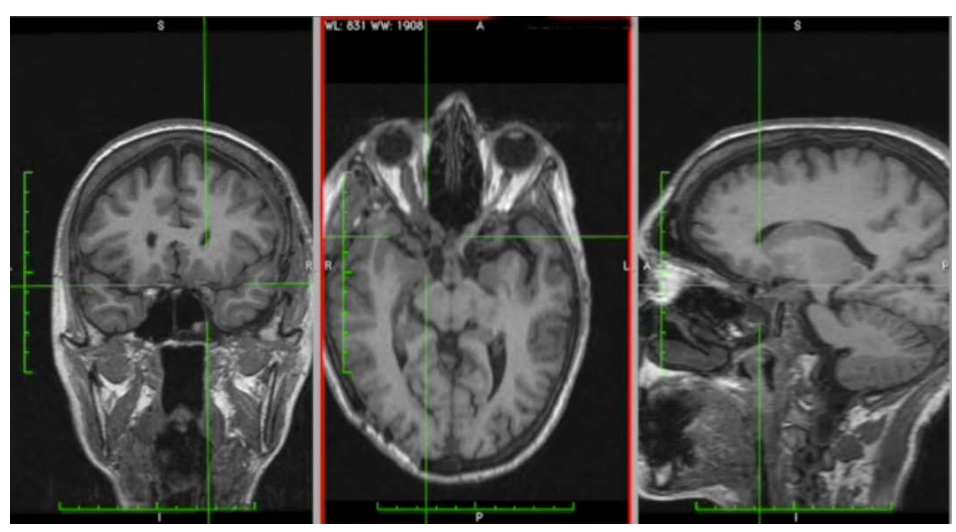

Figure 3. Postoperative MRI presenting complete tumor resection.

\section{Discussion}

The optic nerve metastases arise either through hematogenic or lymphogenic dissemination of primary tumor or as local propagation and seeding from intraocular malignancies. Cases of primary intracranial malignancies seeding to the optic nerve have been described including pinealoma [2], pinealoblastoma [3], teratoma [4], medulloblastoma [5]. The isolated metastases to the optic nerve arising from breast cancer are rare with only 13 cases described in the literature as reported by a recent review [1]. These lesions often present with the clinical and radiological features of optic nerve sheath meningioma-one the more frequently encountered primary tumors of the optic nerve [1] [6]-[9]. Furthermore, the development of metastatic lesion in optic nerve sheath meningioma has also been reported [10]. The diagnosis of these lesions could be further complicated by unspecific presentation as paraneoplastic optic neurits [11] [12].

The optic nerve metastases have most often been misdiagnosed as optic nerve sheath meningiomas. To a significant degree, this is attributable to the much higher incidence of meningiomas in this region. From epidemiological point of view optic nerve meningiomas are predominantly found in women of middle age as would also be the case for breast cancer metastases. The most frequent clinical feature of optic nerve meningiomas-unilateral optic nerve lesion-is also the predominant manifestation of metastases isolated in the optic nerve. Bilateral 
lesion or bitemporal hemianopsia have been described in cases of metastases with chiasmatic involvement.

Optic nerve metastases and nerve sheath meningiomas have very similar imaging characteristics in both CT and MRI studies thus further hindering the correct differentiation between these two types of lesion. Thus, the diagnostic armament is restricted to histological examination of tumor biopsy material. According to the literature and our experience, tumor excision has no effect on survival but achieves local control over the spread of the disease.

This case of breast cancer metastasis to the optic nerve is an example of a rare condition with wide differential diagnosis. The lesions of the optic nerve require extensive diagnostic maneuvers and multidisciplinary approach to the patient. The neurosurgical intervention achieves both histological diagnosis and local control on the expansion of the lesion.

\section{References}

[1] Cherekaev, V.A., Lasunin, N.V., Stepanian, M.A., Rotin, D.L., Grigor'eva, N.N., Vetlova, E.R., et al. (2013) Breast Carcinoma Metastasis to the Optic Nerve: Case Report and Review of Literature. Zhurnal voprosy neirokhirurgii imeni N. N. Burdenko, 77, 42-48.

[2] Baker, G.S. and Rucker, C.W. (1950) Metastatic Pinealoma Involving the Optic Chiasm. Journal of Neurosurgery, 7, 377-378. http://dx.doi.org/10.3171/jns.1950.7.4.0377

[3] Hertle, R.W. and Robb, R.M. (1990) Pinealoblastoma Metastatic to the Optic Nerve. Journal of Clinical NeuroOphthalmology, 10, 95-99.

[4] Hubner, G. (1976) Intracerebral Metastatic Malignant Teratoma in the Region of the Optic Chiasm. Beitrage zur Pathologie, 157, 189-199. http://dx.doi.org/10.1016/S0005-8165(76)80104-7

[5] Garrity, J.A., Herman, D.C., Dinapoli, R.P., Waller, R.R. and Campbell, R.J. (1989) Isolated Metastasis to Optic Nerve from Medulloblastoma. Ophthalmology, 96, 207-210. http://dx.doi.org/10.1016/S0161-6420(89)32912-5

[6] Arai, A., Morishita, A., Hanada, Y. and Aihara, H. (2010) Solitary Metastatic Tumor within the Optic Chiasm—Case Report. Neurologia Medico-Chirurgica, 50, 158-161. http://dx.doi.org/10.2176/nmc.50.158

[7] Backhouse, O., Simmons, I., Frank, A. and Cassels-Brown, A. (1998) Optic Nerve Breast Metastasis Mimicking Meningioma. Australian and New Zealand Journal of Ophthalmology, 26, $247-249$. http://dx.doi.org/10.1111/j.1442-9071.1998.tb01320.x

[8] Baeesa, S.S. and Benoit, B.G. (1999) Solitary Metastasis of Breast Carcinoma in the Optic Chiasm. British Journal of Neurosurgery, 13, 319-321. http://dx.doi.org/10.1080/02688699943763

[9] Fox, B., Pacheco, P. and DeMonte, F. (2005) Carcinoma of the Breast Metastatic to the Optic Nerve Mimicking an Optic Nerve Sheath Meningioma: Case Report and Review of the Literature. Skull Base: Official Journal of North American Skull Base Society, 15, 281-287, Discussion 287-289. http://dx.doi.org/10.1055/s-2005-921935

[10] Arnold, A.C., Hepler, R.S., Badr, M.A., Lufkin, R.B., Anzai, Y., Konrad, P.N., et al. (1995) Metastasis of Adenocarcinoma of the Lung to Optic Nerve Sheath Meningioma. Archives of Ophthalmology, 113, 346-351. http://dx.doi.org/10.1001/archopht.1995.01100030102029

[11] Cho, H.K., Park, S.H. and Shin, S.Y. (2011) Isolated Optic Nerve Metastasis of Breast Cancer Initially Mimicking Retrobulbar Optic Neuritis. European Journal of Ophthalmology, 21, 513-515. http://dx.doi.org/10.5301/EJO.2010.6099

[12] Pengel, J., Crevits, L., Wynants, P., De Poorter, M.C., Mastenbroek, G.G. and De Reuck, J. (1997) Optic Nerve Metastasis Simulating Optic Neuritis. Clinical Neurology and Neurosurgery, 99, 46-49. http://dx.doi.org/10.1016/S0303-8467(96)00559-8 